\title{
KONTROL OPTIMAL PADA PEYEBARAN TUBERKULOSIS DENGAN EXOGENOUS REINFECTION
}

\author{
1J. Nainggolan, ${ }^{2}$ F. J. Iswar, dan ${ }^{3}$ Abraham \\ 1,2,3Jurusan Matematika Fakultas Matematika dan IImu \\ Pengetahuan Alam Universitas Cenderawasih \\ jonn_cesil@yahoo.co.id
}

\section{ABSTRACT}

Tuberculosis is a disease caused by Mycobacterium tuberculosis. Tuberculosis can be controlled through treatment, chemoprophylaxis and vaccination. Optimal control of treatment in the exposed compartment can be done in an effort to reduce the number of exposed compartments individual into the active compartment of tuberculosis. Optimal control can be completed by the Pontryagin Maximum Principle Method. Based on numerical simulation results, optimal control of treatment in the exposed compartment can reduce the number of infected compartments individual with active TB.

Keywords : Exogenous Reinfection, Optimal Control, Pontryagin's Maximum Principle, Spread Of Tuberculosis.

\section{ABSTRAK}

Tuberkulosis adalah penyakit yang disebabkan oleh Mycobacterium tuberculosis. Penyakit tuberculosis dapat dikendalikan melalui pengobatan, chemoprophylaxis dan vaksinasi. Kontrol optimal pengobatan pada kompartemen exposed dapat dilakukan dalam upaya mengurangi jumlah indivdu kompartemen exposed masuk ke kompartemen terinfeksi tuberculosis aktif. Kontrol optimal dapat diselesaikan dengan metode Prinsip Maksimum Prontryagin. Berdasarkan hasil simulasi numeric, kontrol optimal pengobatan pada kompartemen exposed dapat mengurangi jumlah individu kompartemen terinfeksi TB aktif.

Kata Kunc : Exogenous Reinfection, Kontrol Optimal, Prinsip Maksimum Pontryagin, Penyebaran Tuberkulosis. 


\section{PENDAHULUAN}

Tuberkulosis (TB) adalah penyakit infeksi yang disebabkan oleh Mycobacterium tuberculosis sampai saat ini masih masalah di dunia khususnya pada Negara-negara berkembang. Tuberkulosis menyebabkan jutaan manusia sakit setiap tahun dan menempati urutan kedua penyakit infeksi terbanyak yang menimbulkan kematian di seluruh dunia sesudah Human Immunodeficiency Virus (HIV). Berdasarkan laporan WHO, di tahun 2017 (WHO, 2018) diperkirakan ada 1.020 .000 kasus TB di Indonesia, namun baru terlapor ke Kementerian Kesehatan sebanyak 420.000 kasus. Jumlah tersebut mengalahkan Tiongkok di urutan ketiga yang memiliki sekitar 1,4 milyar penduduk. Hanya satu negara yang lebih buruk jumlah kasus TB-nya dari Indonesia, yakni India yang memiliki jumlah penduduk 1,3 milyar.

Pencegahan individu yang susceptible agar tidak terinfeksi penyakit TB dapat dilakukan dengan cara memberikan vaksinasi Baccilus Calmete Guerin (BCG) kepada bayi (umur 2-3 bulan) (WHO, 2018; Nainggolan, 2013). Individu yang divaksinasi BCG dapat memproteksi $70-80 \%$ infeksi penyakit TB. Program pelaksanaan vaksinasi pada tahun 1921, telah terbukti dapat menurunkan jumlah individu yang terinfeksi penyakit TB (Crofton at al. 2002). Penanggulangan individu yang terinfeksi penyakit Tb pasif dapat dilakukan dengan chemoprophylaxis dengan cara memberikan Obat Anti Tuberkulosis (OAT) isoniazid. Pengobatan individu yang sudah terinfeksi penyakit TB aktif, WHO telah merekomendasikan untuk memberikan OAT: isonizid, rifampisin, pirazinamid, etambutol, dan streptomosin untuk diimplementasikan secara bertahap keseluruh unit pelayanan kesehatan di dunia (Crofton at al. 2002).

Penanggulangan penyebaran penyakit tuberkulosis merupakan tanggung jawab pemerintah maupun swasta. Penelitian bidang matematika telah memberikan kontribusi yang cukup signifikan terhadap penanggulangan penyakit tuberkulosis diantaranya: Blower et al. (1995) mengkaji tentang model dinamika transmisi instrinsik epidemik tuberkulosis, Feng et al. (2001) mengkaji model penyakit tuberkulosis dengan memperhatikan variabel exposed yang berdistribusi eksponensial, Castillo-Chavez dan Song (2004) mengkaji model dinamik penyakit tuberkulosis dan aplikasinya, dan Bhunu et al. (2008) mengkaji model penanggulangan penyakit tuberkulosis dengan tindakan chemoprophylaxis dan pengobatan.

Optimalisasi pengobatan atau penanggulangan penyebaran penyakit TB dapat dengan memberikan kontrol optimal terhadap pengobatan, chemoprophylaxis dan vaksinasi (Nainggolan et al., 2014). Penyelesaian metode yang terkenal dan banyak digunakan untuk menyelesaikan masalah kontrol optimal adalah dengan metode Prinsip Maksimum Pontryagin. Prinsip Maksimum Pontryagin dalam kontrol optimal secara teoritis telah dibahas oleh Naidu (2002). 


\section{METODE PENELITIAN}

Metode penelitian ini adalah dengan kajian pustaka, kajian pustaka yang dikaji yaitu memberikan kontrol pada pencegahan penyakit dari kompartemen Exposed (TB pasif) menjadi Terinfeksi aktif TB. Tujuan dilakukan kontrol pencegahan yaitu upaya untuk mengurangi jumlah individu kompartemen Expoxed masuk ke kompartemen TB aktif.

Berdasarkan model matematika penyebaran tuberculosis yang dikaji oleh Zhilan Feng, C. Castillo-Chavez dan Angel F. Capurro dalam jurnal "A Model for Tuberculosis with Exogenous Reinfection" pada tahun 2000, dimana populasi pada model epimedik yang dikaji dibagi menjadi 4 kompartemen, yaitu Susceptible (S) yang menyatakan banyaknya individu yang masih sehat dan rentan terinfeksi penyakit, Exposed (E) yang menyatakan banyaknya individu terinfeksi pasif (laten) yang belum dapat menularkan penyakit ke individu lain, Infectious (I) yang menyatakan banyaknya individu terinfeksi aktif yang dapat menularkan penyakit ke individu lain, serta Treated (T) yang menyatakan banyaknya individu yang sedang menjalani proses pengobatan serta individu yang telah sembuh, namun dapat kembali terinfeksi penyakit.

Pengendalian penyebaran penyakit TB dengan exogenous reinfection dilakukan guna menurunkan jumlah populasi individu TB aktif. Upaya kontrol yang diberikan adalah kontrol pengobatan yang bertujuan untuk mengurangi jumlah populasi individu terpapar dan dapat menularkan bakteri $M$ tb pada rentang waktu terbatas.

Selanjutnya upaya kontrol tersebut dirumuskan pada model epidemi tuberkulosis dengan exogenous reinfection sebagai berikut:

$$
\begin{aligned}
& \frac{d S}{d t}=\Lambda-\beta c S \frac{I}{N}-\mu S \\
& \frac{d E}{d t}=\beta c S \frac{I}{N}-p \beta c(1-u) E \frac{I}{N}-(\mu+k) E+\sigma \beta c T \frac{I}{N} \\
& \frac{d I}{d t}=p \beta c(1-u) E \frac{I}{N}+k E-(\mu+r+d) I \\
& \frac{d T}{d t}=r I-\sigma \beta c T \frac{I}{N}-\mu T \\
& N(t)=S(t)+E(t)+I(t)+T(t)
\end{aligned}
$$

dengan $u \in U=\{u(t) \mid 0 \leq u(t) \leq 1,0 \leq t \leq T\}$.

Variabel $u(t)$ merupakan variabel kontrol, dengan nilai koefisien $1-u(t)$ merepresentasikan upaya untuk mencegah terjadinya reinfeksi guna mengurangi kontak antara individu TB laten dengan individu TB aktif. Jika nilai $u(t)=1$, artinya pencegahan terhadap exogenous reinfection mencapai $100 \%$ efektif, sedangkan jika nilai $u(t)=0$ akan diperoleh model exogenous reinfection TB tanpa kontrol. 


\section{HASIL DAN PEMBAHASAN}

\subsection{Kontrol Optimal Model Penyebaran Penyakit Tuberkulosis dengan Exogenous Reinfection}

Penyelesaian kontrol optimal sistem (1)-(5) diperoleh dengan menerapkan Prinsip Maksimum Pontryagin. Selanjutnya Sistem (1)-(5) disebut sebagai persamaan keadaan (state), dengan fungsional objektif (performance index) sistem diberikan sebagai berikut

$$
\min J(u)=\int_{0}^{t_{f}}\left(I+B u^{2}\right) d t
$$

dengan $I$ adalah kompartemen Infectious, $B$ adalah parameter bobot biaya pengobatan bernilai positif yang bersesuaian dengan kontrol $u(t)$ dan $t_{f}$ adalah waktu akhir periode kontrol. Langkah pertama dalam menyelesaikan masalah kontrol optimal yaitu menentukan fungsi Hamiltonian dari Sistem (1)-(5) dan (6) yaitu sebagai berikut:

$$
\begin{gathered}
H(x(t), u(t), \lambda(t), t)=f(x(t), u(t), t)+\lambda(t) f(x(t), u(t), t)=I+B u^{2}+\lambda_{S}\left(\frac{d S}{d t}\right)+\lambda_{E}\left(\frac{d E}{d T}\right)+ \\
\lambda_{I}\left(\frac{d I}{d T}\right)+\lambda_{T}\left(\frac{d T}{d T}\right)=I+B u^{2}+\lambda_{S}\left(\Lambda-\beta c S \frac{I}{N}-\mu S\right)+\lambda_{E}\left(\beta c S \frac{I}{N}-p \beta c(1-u) E \frac{I}{N}-(\mu+k) E+\right. \\
\left.\sigma \beta c T \frac{I}{N}\right)+\lambda_{I}\left(p \beta c(1-u) E \frac{I}{N}+k E-(\mu+r+d) I\right)+\lambda_{T}\left(r I-\sigma \beta c T \frac{I}{N}-\mu T\right)
\end{gathered}
$$

Selanjutnya untuk menentukan optimum kontrol $u^{*}(t)$ sehingga diperoleh sistem yang optimal, terlebih dahulu dilakukan karakterisasi sistem yang telah diberikan kontrol, yaitu dalam hal ini sistem (1)-(5). Karakterisasi dilakukan dengan menerapkan Prinsip Maksimum Pontryagin pada persamaan Hamiltonian (7), seperti dinyatakan dalam teorema berikut.

\section{Teorema 1}

Misalkan kontrol optimum $u^{*}(t)$ dan $S_{*}(t), E_{*}(t), I_{*}(t), T_{*}(t)$ merupakan penyelesaian yang bersesuaian dengan persamaan (7), terdapat peubah - peubah adjoint $\lambda_{S}, \lambda_{E}, \lambda_{I}, \lambda_{T}$ yang memenuhi:

$$
\begin{aligned}
\frac{\partial \lambda_{S}}{d t}= & \lambda_{S} \mu+\left(\lambda_{S}-\lambda_{E}\right) \beta c \frac{I_{*}}{N_{*}} \\
\frac{\partial E}{d t}= & \lambda_{E} \mu+\left(\lambda_{E}-\lambda_{I}\right)\left(k+p(1-u) \beta c \frac{I_{*}}{N_{*}}\right) \\
\frac{\partial \lambda_{I}}{d t}= & -1+\lambda_{I}(\mu+d)+\left(\lambda_{S}-\lambda_{E}\right) \beta c \frac{S_{*}}{N_{*}}+\left(\lambda_{E}-\lambda_{I}\right) p(1-u) \beta c \frac{E_{*}}{N_{*}}+\left(\lambda_{T}-\lambda_{E}\right) \sigma \beta c \frac{T_{*}}{N_{*}}+ \\
& \left(\lambda_{I}-\lambda_{T}\right) r \\
\frac{\partial \lambda_{T}}{d t}= & \lambda_{T} \mu+\left(\lambda_{T}-\lambda_{E}\right) \sigma \beta c \frac{I_{*}}{N_{*}}
\end{aligned}
$$

dengan syarat batas (transversality) $\lambda_{(i)}\left(t_{f}\right)=0, i=1,2,3,4$ dan kontrol optimal $u^{*}(t)$ yaitu:

$$
u^{*}(t)=\min \left\{1, \max \left\{0, \frac{1}{2 B N_{*}}\left(\lambda_{I}-\lambda_{E}\right) p \beta c E_{*} I_{*}\right\}\right\}
$$




\section{Bukti:}

Berdasarkan penerapan Prinsip Maksimum Pontryagin pada Persamaan (3.12), ditentukan persamaan-persamaan adjoint dan syarat batas sebagai berikut:

$$
\begin{aligned}
\frac{\partial \lambda_{S}}{d t}=- & -\frac{\partial H}{\partial S}=\lambda_{S} \mu+\left(\lambda_{S}-\lambda_{E}\right) \beta c \frac{I_{*}}{N_{*}} \\
\frac{\partial E}{d t}=- & -\frac{\partial H}{\partial E}=\lambda_{E} \mu+\left(\lambda_{E}-\lambda_{I}\right)\left(k+p(1-u) \beta c \frac{I_{*}}{N_{*}}\right) \\
\frac{\partial \lambda_{I}}{d t}=- & -\frac{\partial H}{\partial I}=-1+\lambda_{I}(\mu+d)+\left(\lambda_{S}-\lambda_{E}\right) \beta c \frac{S_{*}}{N_{*}}+\left(\lambda_{E}-\lambda_{I}\right) p(1-u) \beta c \frac{E_{*}}{N_{*}}+ \\
& \left(\lambda_{T}-\lambda_{E}\right) \sigma \beta c \frac{T_{*}}{N_{*}}+\left(\lambda_{I}-\lambda_{T}\right) r \\
\frac{\partial \lambda_{T}}{d t}= & -\frac{\partial H}{\partial T}=\lambda_{T} \mu+\left(\lambda_{T}-\lambda_{E}\right) \sigma \beta c \frac{I_{*}}{N_{*},} \\
\text { dengan } \lambda_{S}\left(t_{f}\right)= & \lambda_{E}\left(t_{f}\right)=\lambda_{I}\left(t_{f}\right)=\lambda_{T}\left(t_{f}\right)=0,
\end{aligned}
$$

Selanjutnya kontrol optimum $u^{*}(t)$ ditentukan dengan meminimumkan $H$ terhadap vektor kontol $u$ yaitu $\frac{\partial H}{\partial u}=0$ sehingga diperoleh $u^{*}(t)=\frac{1}{2 B N_{*}}\left(\lambda_{I}-\lambda_{E}\right) p \beta c E_{*} I_{*}$. Kemudian dilakukan uji turunan kedua untuk mengetahui bahwa $u^{*}(t)$ yang diperoleh telah memenuhi syarat cukup untuk meminimumkan performance index yaitu sebagai berikut. $\frac{\partial^{2} H}{\partial u^{2}}=2 B$, karena $B$ bernilai positif maka, $\frac{\partial^{2} H}{\partial u^{2}}>0$ artinya $u^{*}(t)$ telah memenuhi syarat cukup untuk meminimumkan performance index. Berdasarkan batas $u(t)$ pada himpunan $U=\{u(t) \mid 0 \leq u(t) \leq 1,0 \leq t \leq$ $\left.t_{f}\right\}$ dapat didefinisikan nilai-nilai $u^{*}(t)$ sebagai berikut.

$$
u^{*}(t)=\left\{\begin{array}{c}
0, \quad \frac{1}{2 B N_{*}}\left(\lambda_{I}-\lambda_{E}\right) p \beta c E_{*} I_{*} \leq 0 \\
\frac{1}{2 B N_{*}}\left(\lambda_{I}-\lambda_{E}\right) p \beta c E_{*} I_{*}, 0<\frac{1}{2 B N_{*}}\left(\lambda_{I}-\lambda_{E}\right) p \beta c E_{*} I_{*}<1, \\
1, \quad \frac{1}{2 B N_{*}}\left(\lambda_{I}-\lambda_{E}\right) p \beta c E_{*} I_{*} \geq 1
\end{array}\right.
$$

atau dapat dituliskan dalam bentuk $u^{*}(t)=\min \left\{1, \max \left\{0, \frac{1}{2 B N_{*}}\left(\lambda_{I}-\lambda_{E}\right) p \beta c E_{*} I_{*}\right\}\right\}$.

\subsection{Penyelesaian Kontrol Opimal Model Penyebaran Penyakit Tuberkulosis dengan Exogenous Reinfection}

Penyelesaian kontrol optimal dengan menggunakan metode Runge-Kutta orde empat dengan bantuan software MATLAB R2010a. Simulasi ini dilakukan untuk melihat dinamika penyebaran penyakit tuberkulosis dengan faktor exogenous reinfection pada populasi manusia dengan dan tanpa diberikan kontrol untuk menurunkan laju penyebaran penyakit dalam populasi. Nilai-nilai parameter yang digunakan pada simulasi disajikan pada Tabel 1 dengan nilai awal untuk masing-masing populasi adalah $S_{0}=13250, E_{0}=10500, l_{0}=1000, T_{0}=250$ dengan periode pemberian kontrol adalah selama 5 tahun. 
Tabel 1 : Nilai Parameter Simulasi Numerik

\begin{tabular}{|c|l|c|}
\hline Parameter & \multicolumn{1}{|c|}{ Nilai Parameter } & \multicolumn{1}{c|}{ Sumber } \\
\hline$\Lambda$ & 417 individu per tahun & Asumsi \\
\hline$\beta$ & 80 per tahun & Asumsi \\
\hline$\mu$ & 0,0167 per tahun & Choi dkk (2009) \\
\hline$\sigma$ & 0,9 & Choi dkk (2009) \\
\hline$C$ & 0,1 kontak per kapita per tahun & Asumsi \\
\hline$B$ & 100 & Asumsi \\
\hline$d$ & 0,1 per tahun & Choi dkk (2009) \\
\hline$k$ & 0,005 per tahun & Choi dkk (2009) \\
\hline$p$ & 0,4 & Choi dkk (2009) \\
\hline$r$ & 2 per tahun & Choi dkk (2009) \\
\hline
\end{tabular}

Selanjutnya berdasarkan data Tabel 1 , dinamika perubahan jumlah individu masingmasing kompartemen sebelum dan sesudah diberikan kontrol $u^{*}(t)$ serta fungsi kontrol $u^{*}(t)$ yang digunakan pada Sistem (1)-(5) disajikan dalam bentuk grafik pada Gambar 1.

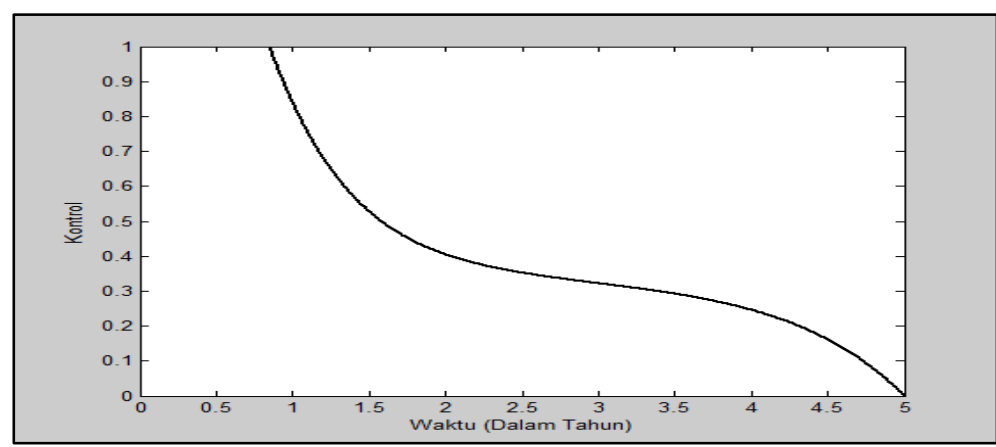

Gambar 1 : Grafik Kontrol Pengobatan Tuberkulosis $u(t)$

Berdasarkan Gambar 1, menunjukkan bahwa upaya pengontrolan dengan pengobatan yang diterapkan memiliki kisaran nilai fungsi yaitu $0,4 \leq u(t) \leq 1$ untuk periode $0-1,5$ tahun. Selanjutnya setelah kurun waktu satu setengah tahun, nilai fungsi kontrol yang diterapkan mengalami penurunan. 


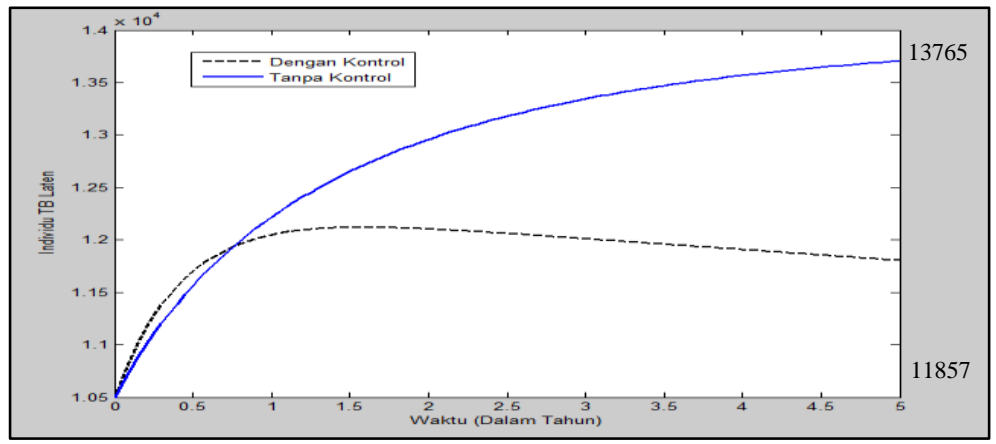

Gambar 2 : Dinamika Jumlah Individu Pada Kompartemen $E$ Dengan Dan Tanpa Pemberian Kontrol $u(t)$

Berdasarkan Gambar 2, jumlah individu kompartemen exposed menurun setelah 9 bulan dilakukan pengontrolan, sedangkan tanpa kontrol jumlah individu kompartemen exposed meningkat sampai tahun ke 6 .

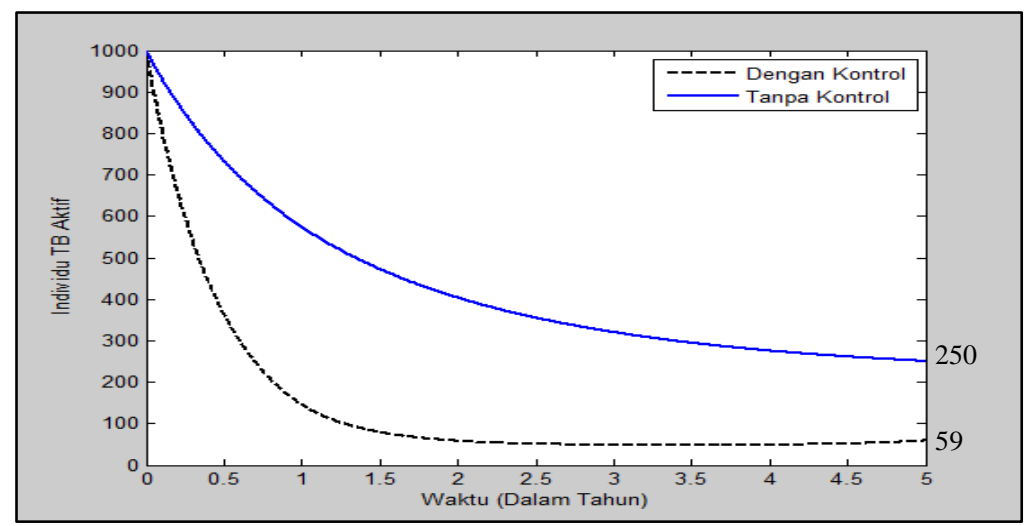

Gambar 3 : Dinamika Jumlah Individu Pada Kompartemen I Dengan dan Tanpa Pemberian Kontrol $u(t)$

Berdasarkan Gambar 3, jumlah individu kompartemen infected dengan kontrol lebih menurun dibandingkan dengan tanpa kontrol mulai dari waktu awal sampai waktu $t=6$ tahun. 


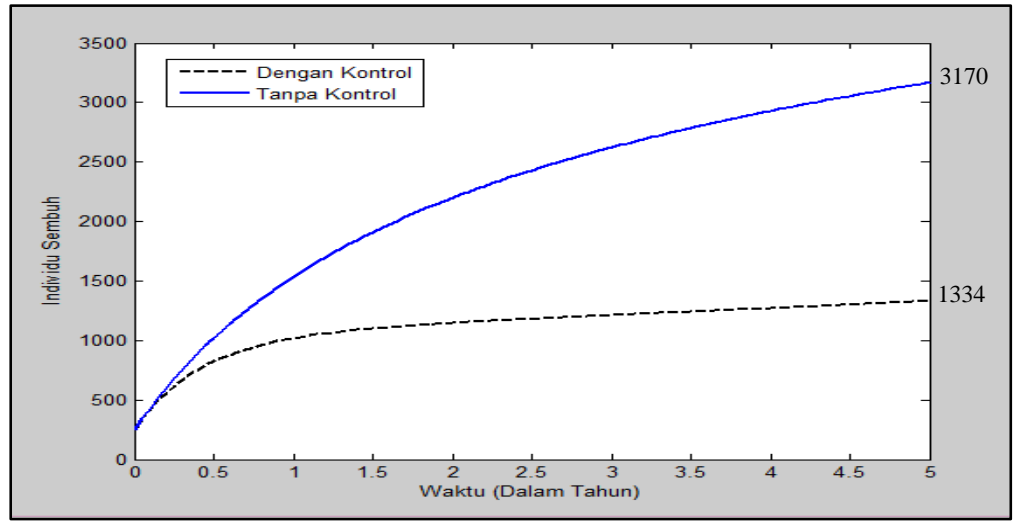

Gambar 4 : Dinamika Jumlah Individu Pada Kompartemen $T$ Dengan Dan Tanpa Pemberian Kontrol $u(t)$

Berdasarkan Gambar 4, jumlah individu kompartemen treated dengan kontrol lebih meningkat dibandingkan dengan tanpa kontrol mulai dari waktu awal sampai waktu $t=6$ tahun.

\section{KESIMPULAN}

Berdasarkan hasil dan pembahasan, diperoleh kesimpulan sebagai berikut:

1. Hasil penerapan Prinsip Maksimum Pontryagin diperoleh kontrol optimal dari model penyebaran penyakit tuberkulosis dengan exogenous reinfection yaitu:

$$
\max \left\{0, \frac{1}{2 B N_{*}}\left(\lambda_{I}-\lambda_{E}\right) p \beta c E_{*} I_{*}\right\}
$$

dengan $B$ adalah parameter bobot biaya pengobatan bernilai positif yang bersesuaian dengan kontrol $u(t)$ serta $\lambda_{E}$ adjoint kompartemen exposed dan $\lambda_{I}$ adalah adjoint kompartemen infected.

2. Berdasarkan simulasi numerik diketahui bahwa tindakan pengontrolan efektif diterapkan untuk menurunkan jumlah individu TB aktif $(I(t))$. 


\section{DAFTAR PUSTAKA}

[1] Bhunu, C.P. et al., Tuberculosis Transmission Model with Chemoprophylaxis and Treatment, Bulletin of Mathematical Biology, 2008, 70: 1163-1191.

[2] Blower, S. M. et al., The Instrinsic Transmission Dynamic of Tuberculosis Epidemic, Nature Medicine, 1995, (1)8, 815-821.

[3] Crofton, S.J., Horne, M., and Miller, F., Clinical Tuberculosis, Mac Milan Education Ltd, 2002, London.

[4] Feng, Z., Castillo-Chavez, C., dan Capurro, A. F., A Model for Tuberculosis with Exogenous Reinfection, Theoretical Population Biology, 2000, 57:235-247.

[5] Naidu, D.S., Optimal Control Systems, CRC PRESS, 2002, New York.

[6] Nainggolan, J., Supian, S., Supriatna, A. K., and Anggriani, N, Mathematical Model of Tuberculosis Transmission with Reccurent Infection and Vaccination, Journal of Physics: Conference Series 423, 2013, 012059, 1-8.

[7] Nainggolan, J., Supian, S., Supriatna, A. K., and Anggriani, N., and Detiatrimargini, Optimal Control Solution of A Tuberculosis Transmission Model with Reccurent Infection and Vaccination Using C\# Programming, Advanced Science Letters: Volume 20, Number 1 Tahun 2014, p. 51-55(5).

[8] WHO, Global Tuberculosis Control 2017, WHO Library Cataloguing-in-Publication Data 2017. 